\title{
EDUCATION AS BASIS OF SUSTAINABLE DEVELOPMENT
}

\begin{abstract}
Andrea FEHER, Banat University of Agricultural Sciences and Veterinary Medicine "King Michael It of Romania" from Timișoara, Romania, 119 Calea Aradului, 300645, Timisoara, Romania, feherandrea.usab@ gmail.com (corresponding author)

Tabita ADAMOV, Banat University of Agricultural Sciences and Veterinary Medicine "King Michael It of Romania" from Timișoara, Romania, 119 Calea Aradului, 300645, Timisoara, Romania, tabitaadamov2003@yahoo.com

Manuela Dora ORBOI, Banat University of Agricultural Sciences and Veterinary Medicine "King Michael Ist of Romania" from Timișoara, Romania, 119 Calea Aradului, 300645, Timisoara, Romania, orboi@ usab-tm.ro

Miroslav RAICOV, Romanian Academy - Branch of Timisoara, Research Center for Sustainable Rural Development of Romania, 24 Mihai Viteazu Bv., 300223, Timisoara, Romania, mikiraicov@gmail.com

Adrian BĂNEȘ, Romanian Academy - Branch of Timisoara, Research Center for Sustainable Rural Development of Romania, 24 Mihai Viteazu Bv., 300223, Timisoara, Romania, adrian.banes@acad-tim.tm.edu.ro

The main objective of the article is to present the level of education in some selected countries, and to explain how education determines a sustainable growth. Education is the main factor to achieve both economic and employment growth. At the same time, education plays an important role for a sustainable improvement of the standard of living in the world. Supporting education is also one of the aims of the 2030 Agenda for Sustainable Development (Goal 4), but education appears in a number of other SDG targets too. The countries that allocate the most capital for education are Norway, Denmark, Sweden, United Kingdom, Belgium, Finland (over 6.7\% of GDP). The share of GDP allocated for education in Romania is only 2.7. This directly affects both the physical conditions for carrying out educational and research activities in school units and the qualitative level of the educational act. The Pearson correlation coefficient (r) between the real GDP/capita (VAR01) and share of GDP for education (VAR02) for our study is 0.694 , which again underlines the close correlation between the allocation of funds for education and research and the level of development from a country. The Pearson correlation coefficient ( $r$ ) between supporting education from GDP and top 100 universities is relatively low ( $r=0.287$ ), reflecting an insufficient correlation between the two variables. As a result, the education system in a country must be adjusted and supported both financially and through the adoption of viable policy decisions that will ensure increased performance in the educational system.
\end{abstract}

Keywords: education, entrepreneurship, GDP, sustainable development, Pearson correlation coefficients

\section{INTRODUCTION}

Sustainable development means that development which satisfies the needs of the present without the detriment to the potential of next generations to fulfil their own needs (World Commission on Environment and Development, 1987).

The concept of sustainable development has undergone continuous changes over the years, reaching nowadays to state that the main objective of sustainable development is to find relevant correlations between systems (economic, social, technological, environmental) (Ciolac et al., 2019), emphasizing, increasingly, on intelligent development, based on education and innovation.

The states that allocate the highest costs for education and research are also those whose economy is based on innovative products and which have an accelerated growth rate (McGuirk et al., 2015). Therefore, education and innovation are the primary factors driving sustainable growth (Feher, 2014).

Education leads to growth and jobs and helps to improve employability, productivity, innovation and competiveness (UN, 2015).

Education is an important objective formulated in the 2030 Agenda for Sustainable Development (UN, 2015).

The objectives of the European Union regarding education as a basis for the development of a smart and sustainable economy are set at SDG4 ( Ensure inclusive and equitable quality education and promote lifelong learning opportunities for all). The targets broaden the scope of education as a global project to encompass outcomes in literacy, numeracy, and wider learning including global citizenship, sustainability and gender equality (Unterhalter, 2019).

Education is also a precondition for achieving many other Sustainable Development Goals (SDGs) (UN, 2015).

Educational issues appear in a number of other SDG targets, including SDG3 on good health and wellbeing, SDG 5 on gender equality and women's empowerment, and SDG8 on decent work (Feher, 2019). While it is acknowledged that in some SDGs the education components and connections could be better articulated (Nillson, 2016), the SDG framework has been read as offering something for everyone working on education (UNESCO, 2016).

\section{RESEARCH METHODS}

The starting point for the research results presented in this article is a statistical analysis of the level of development of each country, expressed by the statistical indicator GDP/capita, the expenses allocated for education and higher education expressed as a percentage of GDP, and the number of universities in each analysed country which are among the top universities in Europe.

Copyright (C) 2019 The Authors. Published by Vytautas Magnus University. This is an open-access article distributed under the terms of the Creative Commons Attribution License (CC-BY 4.0), which permits unrestricted use, distribution, and reproduction in any medium, provided the original author and source are credited. 
Statistical indicators are real numbers, which synthesize part of the information contained in a set of values, giving the possibility of global appreciation of the whole series, instead of taking into account each value in the string (Rujescu, 2015; Raicov et al., 2018).

Minimal and Maximal are indicators that indicate the value range of the value series. Minimal is the smallest value in the series, and Maximal is the highest.

Average is the indicator that shows the central trend of the value series, and usually shows where the data tend to clutter. Often, the values in the series are mostly near the average, and a smaller part of them are located to the left or right of the media.

To show the existing correlation between the evolution of GDP/capita (as a form of expression of economic development) and the expenses allocated to education at the level of the analysed countries, on the one hand, and the relation between the expenses allocated to education and the hierarchy of universities (which expresses the recognition of the educational act) we used the calculation of the PEARSON correlation coefficients.

The bivariate Pearson Correlation produces a sample correlation coefficient $(r)$, which measures the strength and direction of linear relationships between pairs of continuous variables (Băneș, 2018; Rujescu, 2015).

\section{RESEARCH RESULTS}

In Figure 1 we have presented the average value of Gross Domestic Product / capita of the years 2014-2018. Real GDP/capita is a measure of economic activity and is also used as a proxy for the development in a country's material living standards (Feher et al., 2017, Eurostat, 2019). It is calculated as the ratio of real GDP to the average population of a specific year.

The lowest values of the indicator are found in the Nordic countries, Norway having an average GDP/capita of 68,400 Euros in the period 2014-2018, Switzerland 58,460 Euros, Denmark 46,300 Euros. The value of the indicator decreases as we move to Eastern European countries. In countries where GDP/capita is highest, the standard of living of the population is significantly higher.

Considering the scale of the countries taken for analysis, the ratio between Romania (last country) and Norway (the first on the scale considering the value of GDP/capita) is 1: 8.7. This directly affects the quality of life, including the level of education in each country, as a premise for sustainable development.

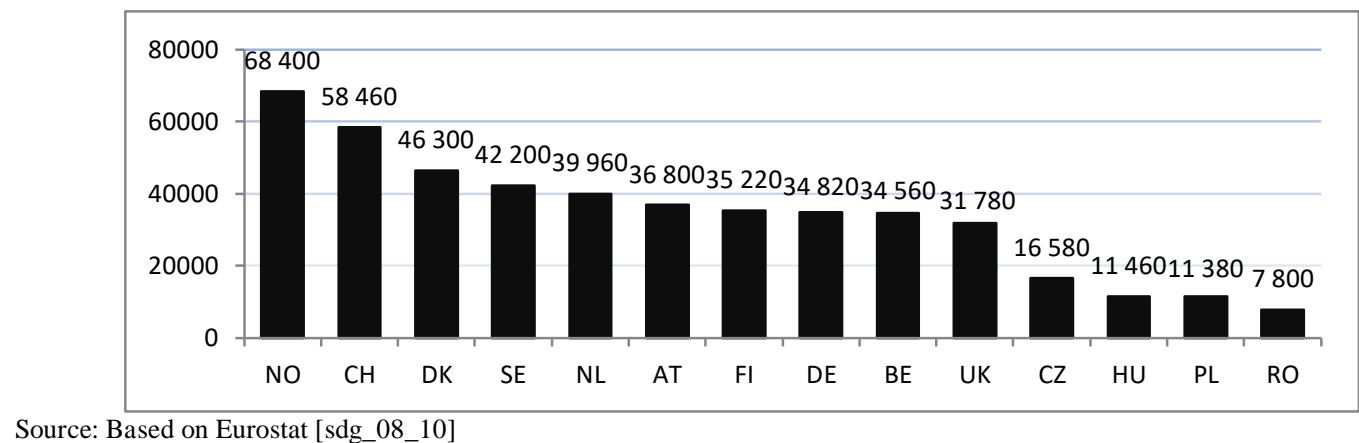

Source: Based on Eurostat [sdg_08_10]

Figure 1. Real GDP per capita (EUR/capita, the average value of the years 2014-2018)

Another indicator analysed in the article concerns the financial support of the education system in the countries taken for the study, expressed as a weight that is allocated to education from Gross Domestic Product. The situation is presented in Figure 2, and the values reflect the average of the years 2012-2016.

Unfortunately, the education system in Romania benefits from the weakest financial support in all analysed countries. The same situation is found in the case of supporting research and development (Figure 3). Hungary allocates 1.5 times more capital to education, the Netherlands two times more, Denmark and Norway nearly three times more money to education than Romania. This directly affects both the physical conditions for carrying out educational and research activities in school units and the qualitative level of the educational act. The correlation will also be supported by presenting the number of universities in these countries that are in the European ranking of prestigious universities.

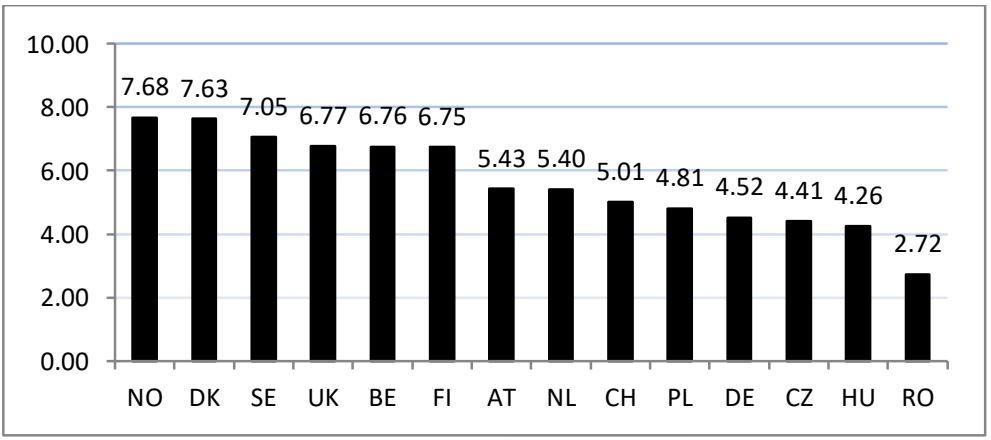

Source: Based on Eurostat, [educ_uoe_fini01] and [nama_10_gdp]

Figure 2. The share of GDP allocated for education in several European countries 


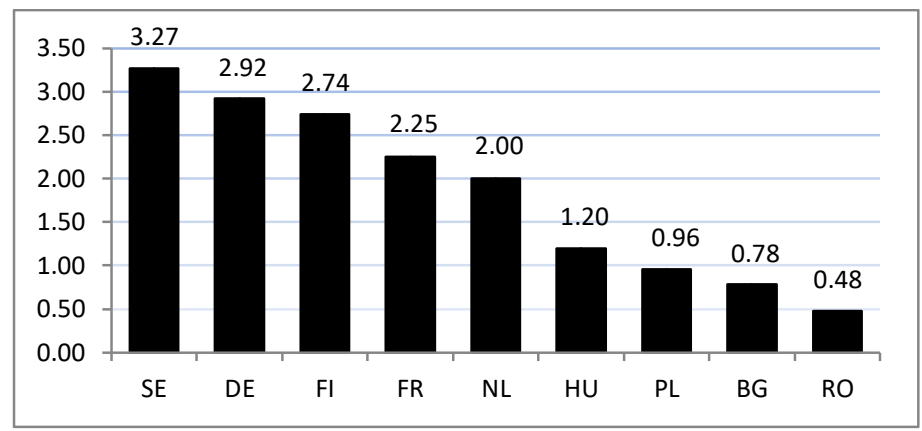

Source: Based on Eurostat, [rd_e_gerdtot] and [nama_10_gdp]

Figure 3. The share of GDP allocated for research and development in several European countries

If we refer strictly to the tertiary education, the support of this form of education is shown in Figure 4, expressed as the weight allocated from the Gross Domestic Product.

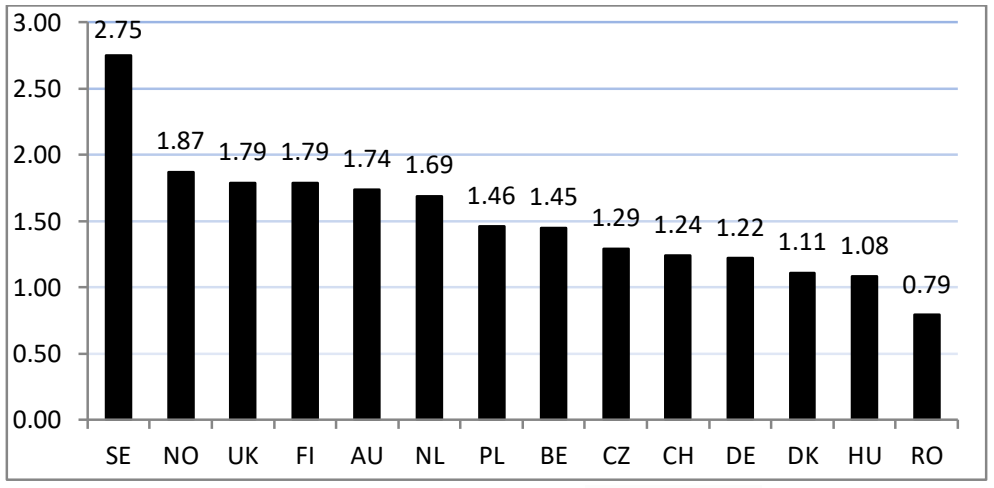

Source: Based on Eurostat, [educ_uoe_fini01] and [nama_10_gdp]

Figure 4. The share of expenditure on tertiary education from GDP in several European countries

The country that allocates the most money to higher education is Sweden, $2.75 \%$ of GDP, followed by Norway with $1.87 \%$ of GDP, United Kingdom $1.79 \%$, and last in the group of countries analysed we find Romania, with a support of tertiary education of only $0.79 \%$ of the GDP.

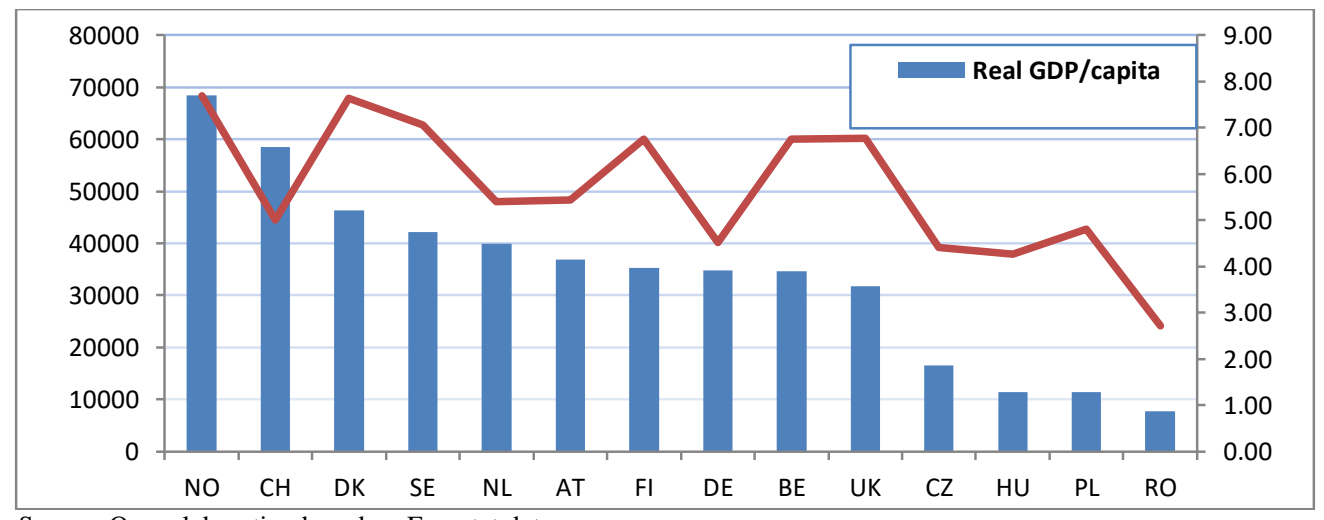

Source: Own elaboration based on Eurostat data

Figure 5. The relationship between GDP/capita and share of expenditure allocated for education from GDP

For analysis the relationship between real GDP/capita and share of expenditure allocated for education we used the PEARSON correlation coefficient (Table 1).

The bivariate Pearson Correlation produces a sample correlation coefficient $(r)$, which measures the strength and direction of linear relationships between pairs of continuous variables. The Pearson's " $r$ " for the correlation between the Real GDP/capita (VAR01) and share of GDP for education (VAR02) in our example is 0.694. When Pearson's "r" is close to 1 this means that there is a strong relationship between the two variables. So, education is a main factor that determines the evolution and size of Gross Domestic Product, and, finally, the sustainable development of a country. Also, when Pearson's "r" is positive $(+)$ this means that as one variable increases in value, the second variable also increase in value. Similarly, as one variable decreases in value, the second variable also decreases in value.

Regarding the Sig (2-Tailed) if the value is less than or equal to 0.05 (the value is 0.006 in our case), we can conclude that there is a statistically significant correlations between the two variables.

Table 1. Pearson correlation coefficients 


\begin{tabular}{|l|l|r|r|}
\hline \multicolumn{2}{|c|}{} & \multicolumn{1}{|c|}{$\begin{array}{c}\text { VAR02 } \\
\text { VAR01 } \\
\text { Real GDP/capita }\end{array}$} \\
\hline \multirow{3}{*}{ VAR02 } & Pearson Correlation (r) & 1 & 0.694 \\
\cline { 2 - 4 } & Sig. (2-tailed) & - & 0.006 \\
\cline { 2 - 4 } & $\mathrm{N}$ & 14 & 14 \\
\hline \multirow{3}{*}{ VAR01 } & Pearson Correlation (r) & 0.694 & 1 \\
\cline { 2 - 4 } & Sig. (2-tailed) & 0.006 & - \\
\cline { 2 - 4 } & $\mathrm{N}$ & 14 & 14 \\
\hline
\end{tabular}

In Figure 6 we show the distribution by country of the universities in the European rankings - top 100, 200, 500, and 1000. Thus, United Kingdom has seven universities in the top 100 universities in Europe, Germany, Netherlands and Sweden have three universities in the top 100, Belgium and Denmark two universities, Finland and Norway each one university in the top 100, the rest of the countries do not have university in this ranking. At the level of the first mentioned countries we observe an increased number of universities in the top 200, 500 and 1000.

The universities in the top 100, 200 and even 500 come generally from small and medium-sized European countries, which have an obvious qualitative and quantitative critical mass, in which over 6\% of GDP is allocated for education and research and 1.5-2.8\% for higher education (Otiman, 2019).

Regarding the ranking of the Romanian universities internationally, this is totally unsatisfactory. Out of a total of 95 universities (56 state universities and 39 private universities, at the level of 2017) (Eurostat, 2019), in Romania only two universities are in the European ranking. These are the University of Bucharest and the Babes-Bolyai University of Cluj-Napoca. The rest of the universities do not meet the qualitative (regarding the educational and research activity) and / or quantitative criteria regarding the number of students in order to be included in the ranking of the prestigious universities.

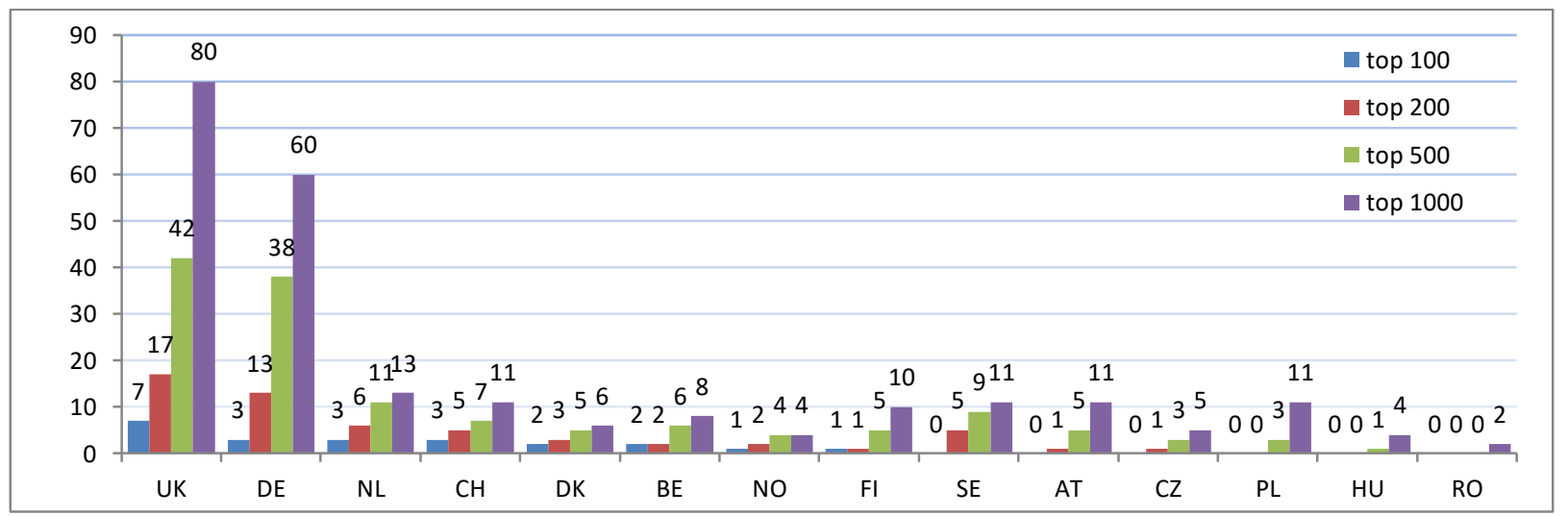

Source: Based on https://www.webometrics.info

Figure 6. Distribution by country of the universities in European rankings - Top 100, 200, 5000, 1000

The Pearson correlation coefficient (r) between supporting education from GDP and top 100 universities is relatively low $(\mathrm{r}=0.287)$, reflecting an insufficient correlation between the two variables. As a result, the education system in a country must be adjusted and supported both financially and through the adoption of viable policy decisions that will ensure increased performance in the educational system.

Of course, the bad situation of educational system from Romania is the result of an inadequate financial support from the public budget and the lack of a clear medium and long term strategy, but this situation is also due to other negative structural factors faced by the universities, namely:

- a small number of students (about 5,000-6,000 students on average at a university and 400-500 staff, compared to 35,000-40,000 students and 4,000-4,500 staff at the top universities);

- high share of costs related to non-academic staff;

- the defective structure of the expenditures destined to the actual education process, where the share of personnel expenses exceeds $50 \%$, and the part that belongs to the actual academic process (equipment, consumables, documentation-information, depreciation) is extremely low (Băneș, 2015, Otiman, 2019 ).

\section{CONCLUSIONS AND DISCUSSION}

Education is one of the main factors that influence the level of development of a country, both economically, socially and culturally.

Continuing education after the basic level is important because people with higher qualifications are more likely to be employed and less likely to face poverty in a knowledge-based economy. Therefore, investing efficiently in education and training systems that deliver high-quality and up-to-date services lays the foundation for a country's prosperity. 
The Pearson correlation coefficient (r) between the real GDP/capita (VAR01) and share of GDP for education (VAR02) for our study is 0.694 , which again underlines the close correlation between the allocation of funds for education and research and the level of development from a country. Also, regarding the Sig (2-Tailed) which value is 0.006 in our case emphasizes that there is a statistically significant correlations between the two variables.

The countries that allocate the most capital for education are Norway, Denmark, Sweden, United Kingdom, Belgium, Finland (over 6.7\% of GDP). The share of GDP allocated for education in Romania is only 2.7. This directly affects both the physical conditions for carrying out educational and research activities in school units and the qualitative level of the educational act.

The Pearson correlation coefficient ( $\mathrm{r}$ ) between supporting education from GDP and top 100 universities is relatively low $(r=0.287)$, reflecting an insufficient correlation between the two variables. As a result, the education system in a country must be adjusted and supported both financially and through the adoption of viable policy decisions that will ensure increased performance in the educational system.

\section{REFERENCES}

1. Băneș A., Orboi M.D., Lile R., Merce I. 2015. Requirements of students for further integration on labor market. International Journal of Learning and Teaching, Vol. 7(2), pp. 50-55 https://doi.org/10.18844/ijlt.v7i2.168

2. Băneş A., Goşa V., Iancu T., Orboi M.D. 2018. Analysis of the Influence of Investments in Tourism Accommodation in Romania, Proceedings of the international conference of life science, USAB Timisoara

3. Ciolac R., Adamov T., Iancu T., Popescu G., Lile R., Rujescu C., Marin D. 2019. Agritourism - A Sustainable Development Factor for Improving the 'Health' of Rural Settlements. Case Study Apuseni Mountains Area. Sustainability, Vol. 11(5), pp. 1467 https://doi.org/10.3390/su11051467

4. Eurostat online database. https://ec.europa.eu/eurostat/data/database. [sdg_08_10], [nama_10_gdp], [educ_uoe_fini01], [rd_e_gerdtot]

5. Feher A. 2014. Development opportunities of rural entrepreneurship by participating in training projects. Research Journal of Agricultural Science, Vol. 46(4), pp. 46-51

6. Feher A., Goșa V., Raicov M., Harangus D., Condea B.V. 2017. Convergence of Romanian and Europe Union agriculture evolution and prospective assessment. Land Use Policy, Vol. 67, 670-678 https://doi.org/10.1016/j.landusepol.2017.06.016

7. Feher A.A., Sîrbulescu C.E., Pașcalău R., Goșa V., Raicov M. 2019. Quality education for all: an investigation of the European Union context using 2030 Agenda indicator. Lucrări Științifice Management Agricol, Vol. 21(2), pp. 112-119

8. McGuirk H., Lenihan H., Hart M. 2015. Measuring the impact of innovative human capital on small firms' propensity to innovate. Research Policy, Vol. 44 (4), pp. 965-976 https://doi.org/10.1016/j.respol.2014.11.008

9. Nillson M., Griggs D., Visbeck M. 2016. Map the Interactions between Sustainable Development Goals. Nature, Vool. 534(7607), pp. 320-323 https://doi.org/10.1038/534320a

10. Otiman P.I. 2019. Metropolitan University (comprehensive) - the university of the future in Romania. Academica, XXIX, Vol. 6-7, pp. 124-130

11. Raicov M., Rujescu C.I., Feher A., Merce I. 2018. The determination and ranking of factors bearing an influence over the ability to absorb rural development funds in Timis County, Romania. AIP Conference Proceedings, Vol. 1978, No. UNSP 390006-1; https://doi.org/10.1063/1.5043990

12. Rujescu C. 2015, Mathematical statistics, ArtPress, Timisoara

13. Unterhalter E. 2019 The Many Meanings of Quality Education: Politics of Targets and Indicators in SDG4. Global Policy, Vol. 10, Supp. 1, pp. 39-51 https://doi.org/10.1111/1758-5899.12591

14. UN (United Nation). 2015. Sustainable Development Goals, United Nations, New York, USA. Available at: https://www.un.org/sustainabledevelopment/sustainable-development-goals/ (accessed on 23/07/2019)

15. UN (United Nation). 2015. Transforming our world. The 2030 Agenda for Sustainable Development, A/RES/70/L.1. Resolution adopted by the General Assembly. United Nations, New York, USA. Available at: https://sustainabledevelopment.un.org/post2015/ transformingourworld/ publication (accessed on 23/07/2019)

16. UNESCO. 2016. Education for People and Planet. Global Education Monitoring Report, Paris, UNESCO

17. World Commission on Environment and Development (WCED). 1987. Our Common Future. Available at: https://sustainabledevelopment.un.org/content/documents/5987our-common-future.pdf (accessed on 10/08/2019) 